\title{
Shocks to issue salience and electoral competition
}

\author{
Enriqueta Aragonès ${ }^{1}$ (D) Clara Ponsati $^{2}$
}

Received: 21 October 2021 / Accepted: 9 January 2022 / Published online: 14 February 2022

(c) The Author(s) 2022

\begin{abstract}
We propose a two party electoral competition model to analyze the effects of an exogenous shock over the relative issue salience on the strategic policy choices of the parties. We find that both parties strategically shift their policy choices from their ideal points towards the ideal point of the median voter of the newly salient issue. The polarization of the distribution of the voters preferences produces a disadvantage for one of the parties, which is forced to implement a large policy shift. We argue that a large policy shift may break a party internal balance among its different factions, which in turn may produce important disruptions in the party system. We illustrate our arguments with an analysis of recent events in Catalonia and the UK.
\end{abstract}

Keywords Preference shock · Relative salience · Party consistency

\section{JEL Classification D72}

"Not all issues flow with predictability from past decisions. The violent civil disorders of the 1960s or the OPEC oil boycott blow up like summer thunderstorms and burst upon the country in magnified form via the mass media. A great national crisis suddenly is proclaimed by commentators and citizens alike and Senators are expected to take immediate action. 'Pressing problems' of this kind force their way onto the Senate's agenda, whether or not feasible solutions are in sight. Action of some kind, even if it is merely symbolic, must be taken as quickly as possible.

\footnotetext{
Aragonès acknowledges financial support by the Generalitat de Catalunya grant number 2017SGR-1359, the Spanish Ministry of Science, Innovation and Universities grant number PGC2018097898-B-100, and the Barcelona School of Economics through the Severo Ochoa Programme for Centres of Excellence in R\&D CEX2019-000915-S.
}

Enriqueta Aragonès

enriqueta.aragones@iae.csic.es

Clara Ponsatí

clara.ponsatiobiols@europarl.europa.eu

1 Institut d'Anàlisi Econòmica, CSIC, Campus UAB, 08193 Bellaterra, Spain

2 European Parliament, Wiertzstraat 60, 1047 Brussels, Belgium 
Problems of this type have arisen frequently in the past few decades, catching most Senators by surprise. They occur almost randomly and when they arise displace all other agenda items that can be delayed or pushed aside."

(Walker 1977, p. 426)

\section{Introduction}

Unexpected events like terrorist attacks, natural disasters, political scandals or even sports results have impact on voters' moods and policy preferences and thus unravel important political consequences. This paper examines how, in a context of electoral party competition, the proposals of political parties adjust to respond to such sudden changes in voters' preferences.

When an exogenous shock affects the policy preferences of voters, the equilibrium that competing political parties had attained prior to the shock is upset. Changes in voters' preferences change voting decisions and parties must realign their policy positions in order to react optimally. The magnitude of the policy shifts needed by each party depend on the magnitude of the shift produced on the voters' preferences, and thus, on the intensity of the shock, but also on the optimal reaction to opponents' re-adjustments. Changes in voter's preferences favour some parties and damage others. Hence, the optimal policy revisions that follow after a preference shock are asymmetric across parties.

An exogenous shock can affect the voters' policy preferences and their voting behavior in two different ways. On the one hand, a shock might shift the voters' ideal points on a given issue. For example, in the case of a terrorist attack it is plausible to think that all voters shift their preference towards an increase in national security. Thus, in the policy dimension affected by the shock, the ideal points of all voters change and they all change in the same direction. On the other hand, a shock may change the balance between the different policy dimensions. Voters are likely to shift their attention to the policy dimension affected by the shock, and regard it as more important and relevant. Thus the salience of a previously unimportant policy dimension may increase, turning it into the dominating issue after the shock.

A preference shock benefits some parties and hurts others. When a shock drives the ideal policy of all voters closer to the ideal policy of a given party, then this party will enjoy an electoral advantage because earning each vote becomes cheaper in ideological cost: to attract votes after the shock this party must make policy proposals that are closer to his ideal points than the policies required prior to the shock. At the same time, for a party with opposed views, the shock causes a disadvantage because the shock drives the voters' ideal points away from the ideal policy of the party. Each single vote becomes more expensive in ideological cost after the shock: to attract votes after the shock requires policy choices further away from his ideal points than those proposed before the shock. Consequently, the parties' policy adjustment as a reaction to a voters' preference shift are asymmetric.

A main focus of our interest are the consequences of a preference shock that changes the relative salience of issues; that is, situations where voters' attention 
shifts unexpectedly and an issue that was previously disregarded suddenly becomes the relevant dimension of political competition. When voters turn their attention to a new issue their decisions are based on their evaluation of the parties' policies on this new salient issue, and parties must strategically choose policy positions on the new relevant issue. If the two parties have different ideal points in this new salient issue, then they will move to compete in the new dimension, aiming to attract the voters with ideal points located between their opposed ideal points. Party competition in the new issue may face a symmetric distribution of voters, in which case both parties will optimally moderate a bit their positions. But, the new salient issue may be one where voters' views are closer to one of the two parties; thus one party is favored by the proximity of the median voter to its ideal point and the other party is damaged by the larger distance between the median voter and its ideal point. In this case, the optimal policy choices of parties would imply asymmetric moves from their ideal points. This is the scenario where the shock delivers the most interesting consequences while maintaining the electoral competition among the initial parties. There is one last possible scenario: If both parties hold similar positions regarding the new issue, i.e. both parties share the same ideal point in the new salient issue, then new parties may find it profitable to enter the electoral competition with proposals that confront the one shared by the two old parties, so that the change on issue salience might break up the stability of the party system. We focus our analysis on the case with asymmetric voters' preferences. In particular, we consider the effects of a polarized preference distribution.

To analyze these phenomena we construct a model of two party electoral competition with policy motivated parties and sincere voters. We assume that there is a decisive voter whose ideal point is unknown to the parties and parties have beliefs about it that are common and common knowledge. In this model we introduce two assumptions that relate closely to the two effects described above: an exogenous shock produces an increase of the salience of a given policy dimension and in this dimension the voters' preferences are polarized. We characterize the equilibrium policy choices of two parties that compete in an election both before and after the shock takes place, and compare the different outcomes that arise.

In equilibrium, parties that are policy motivated choose policies that are moderate compared to their ideal points. If they compete on a dimension with a uniform distribution of the voters' preferences then the policies chosen by the parties are symmetric with respect to the expected location of the ideal point of the decisive voter (the median voter). These results are in line with the ones described in Calvert (1985) and Wittman (1977, 1983). If parties compete on a dimension with an asymmetric distribution of the voters' preferences then the policies chosen by the parties will moderate following the direction of the asymmetry of the distribution of the voters' preferences and the magnitude of the adjustment will be different for each party. In fact, if the distribution of the voters' ideal points is biased to one side of the policy space then the ideal point of the decisive voter will be relatively closer to the ideal point of one of the two parties, and away from the ideal point of the other party. This implies that one party benefits from the shock while the other party suffers damage. The party that is damaged by the shock needs a greater adjustment in its policy proposal in order to remain 
competitive in the electoral contest, while the party favored by the shock needs a smaller change, only to react to his opponent change of strategy. Thus, compared to the policies chosen prior to the shock, the policy choice of the party disfavored by the shock is more moderate, while the policy of the party favored by the shock can be less moderate (closer to the party's ideal point).

The equilibrium policies chosen by the parties depend on the relative salience that the voters assign to each of the issues. The more salient an issue the more moderate are the parties' policy choices on that issue. In particular, if only one issue is salient, that is, under the assumption that voters base their voting decision only on the policy proposals regarding the issue they consider most important then the equilibrium policies on the salient issue coincide with the outcomes of a one-dimensional model, while the equilibrium policies on the non salient issue coincide with the parties' ideal points. Indeed, there is no reason for the parties to compromise their policy positions on an issue if voters are not paying attention to it.

When a shock changes the issue that voters consider salient, both parties react by a substantial moderation of their choices, moving their policies towards the ideal point of the expected median voter, in the newly relevant dimension, while they turn radical, towards their ideal points in the dimension that is no longer salient. More interestingly, if the shock increases the salience of an issue for which the voters' preferences are polarized in an asymmetric way the in equilibrium parties may react by choosing divergent policies. The party that is damaged by the shock reacts by moderating a lot its policy, while the party favored by the shock does not need to moderate its policy so much. However, now the outcomes after the shock have to be compared to the parties' ideal points on that dimension, since this was their optimal choice prior to the shock, when the affected issue was not salient. We also find that if the distribution of voters' preferences after the shock are very asymmetric in equilibrium parties do not moderate their policies at all. Instead they choose to implement their ideal points. We offer a characterization of the conditions on the parameter values of the voters' distribution that produce each type of equilibrium outcomes.

The asymmetry in policy reactions that follows whenever a shock affects the voters' relative issue salience, is consistent with the empirical evidence provided by Plümper and Epifanio (2015). They analyze the changes in antiterrorist policies implemented by incumbents of different countries after a terrorist attack. They find that the intensification of antiterrorist policy is greater for leftist incumbents than for rightist incumbents. The formal arguments developed here offer a theoretical explanation for the empirical observation provided by Plümper and Epifanio.

Our results also point out that shocks that induce changes in relative issue salience may affect the electoral balance between the two competing parties. By favoring one party over the other, the shock imposes different electoral costs to the parties: it makes electoral competition much lighter for one party and much more costly for the other. Implementing a large policy shift may be very costly for a party, because compromising ideological principles may cause internal frictions among the different factions within the party and may end up destroying the party's internal equilibrium. At the same time, when a shock brings to salience a new policy issue, if the positions of established parties on the new issue are too similar, the shock might induce the entry of new parties and reconfiguring the political landscape. 
We illustrate this argument with a discussion of the recent political upheaval in Catalonia and the United Kingdom. In 2010 high court decisions in Spain boosted the salience of the independence issue among Catalan voters'. As a consequence the two main political parties faced demands for drastic changes in their policy proposals and suffered major crisis. The Catalan party system of more than thirty years has been knocked down. The Brexit referendum is another shock that has turned on the salience of a previously disregarded issue and brought about a major crisis in the political party system.

The rest of the paper is organized as follows. In the next section we argue that unexpected events that change the relative issue salience and may also polarize the voters' preferences are a relevant fact and we review the empirical evidence that supports this claim. Section 3 turns to the theoretical model. In Sect. 4 we examine the effects of an increase of salience of an issue where voters' preferences are polarized on the parties' equilibrium policy choices. In Sect. 5 we illustrate how changes in issue salience that require a large policy shift cause instability on party's internal consistency. Section 6 concludes with some final remarks.

\section{Do unexpected events change voter's preferences?}

It is commonly argued that the policy preferences of the voters are conditioned and even determined by the policy stands of the parties during campaigns, and by the policies implemented by incumbents. Indeed, it is in the interest of the parties to try to manipulate voters' opinions through the media, and electoral campaigns. This priming phenomenon is discussed in numerous experimental and empirical studies in psychology, political psychology and political science including Bartels (2006), Iyengar (1990), Iyengar and Kinder (1987), Iyengar et al. (1982), Kahneman and Tversky (1979, 1981, 1984), Krosnick and Kinder (1990), Sheafer and Weimann (2005). For a critique, see also Lenz (2009). Similarly, the literature on policy and policy preference responsiveness (Barbera et al. 2019; Clinton 2006; Kastellec et al. 2015) shows that policy agendas are mainly driven by the political parties, and finds weak empirical support for the claim that politicians are responsive to the general public.

However, public opinion and voter's preferences are also shaped by dramatic, unexpected events that are exogenous to parties' actions. This has long been recognized in the literature on agenda-setting, that identifies "focusing events" as a leading cause for changes in public opinion and shifts in the political debate (Bangartner and Jones 1993; Birkland 1998; Kingdon 1995; Walker 1977). According to Birkland (2017) p. 74: “ Focusing events are sudden, relatively rare events that spark intense media and public attention because of their sheer magnitude or, sometimes, because of the harm they reveal. Focusing events thus attract attention to issues that may have been relatively dormant. Examples of focusing events include terrorist attacks (September 11, 2001 was, certainly, a focusing event), airplane accidents, industrial accidents such as factory fires or oil spills, large protest rallies or marches, scandals in government, and everyday events that gain attention because of some special feature of the event. Two examples of the latter are the alleged beating of motorist 
Rodney King by the Los Angeles Police Department in the early 1990s and O. J. Simpson's murder trial in 1995; the Rodney King incident was noteworthy because, unlike most such incidents, the event was caught on videotape, while the Simpson trial was noteworthy because of the fame of the defendant. Focusing events can lead groups, government leaders, policy entrepreneurs, the news media, or members of the public to pay attention to new problems or pay greater attention to existing but dormant (in terms of their standing on the agenda) problems, and, potentially, can lead to a search for solutions in the wake of perceived policy failure."

There is a substantial empirical literature documenting the effects of dramatic, extraordinary events on public opinion and election outcomes. Studies examine the consequences of nuclear power accidents (van der Brug 2001), natural disaster and accidents involving loss of life (Birkland 1998; Slovic et al. 1984), the assassinations of important social or political figures such as Martin Luther King (Hofstetter (1969)) or terrorism attacks. Balcells (2018) examine eight violent attacks perpetrated between 1989 and 1997 by the a Basque terrorist organization Euskadi Ta Askatasuna (ETA). They measure the effect of attacks on public opinion surveys that were being fielded when the attacks occurred to estimate the causal effect of terrorist violence on individuals' intent to participate in elections as well as on professed support for the incumbent party. They find that terrorist attacks significantly increase individuals' intent to participate in a future election (with a greater impact in attacks against civilians) but find no evidence that the attacks change support for the incumbent party. In general, identifying the causal effect of exogenous shocks on voters' preferences is not a simple exercise. Muñoz et al. (2019) review studies that exploit the role of exogenous shocks during the fieldwork of public opinions surveys taking them as natural experiments to explore causal estimates, and discuss the general strengths and limitations of this identification strategy.

The terrorist attacks of March 2004 in Madrid and their impact in the subsequent election to the Spanish Congress is an interesting case. On March 11, only three days before the election, a major Islamist terrorist attack killed 193 people and injured around 2000. Polls taken before the bombings showed a clear advantage of the incumbent conservative party over the socialist party. However the actual vote delivered a clear victory to the socialist party. The important difference between the results of the polls taken before the attack and the election results seemed to indicate that the voters might have changed their vote intention as a result of the bombings. Indeed, the conservative party, incumbent at that time, might have been considered by many as responsible of the attack, because of the government decision to support the US and UK in Iraq sending Spanish military forces just a few months prior to the election. Instead, in his electoral platform, the socialist leader had promised to bring the troops back home in case of victory. Papers that analyze the relationship between the attacks and the election results on the Spanish congress using post election surveys deliver inconclusive results. While the results of Bali (2007) seem to imply that the bombings were decisive, Lago and Montero (2005) find that they had no effect. Montalvo $(2011,2012)$ takes a different approach; instead of survey responses he examines actual voting results. He compares the outcome of the vote on election day with a control group of individuals that voted before the terrorist attacks: residents abroad had cast their vote before March 7 at a Spanish consulate or by post, thus 
they voted before the bombing took place. It turns out that the results of the vote for this control group showed an advantage to the conservative party, as predicted by the polls, and their turnout participation level was consistent with the normal trend of previous elections. Instead, the votes cast on election day, after the bombings, reversed the results predicted by the polls and showed a significant advantage for the socialist party over the conservative party and, in addition, a significant increase in turnout compared to previous congressional elections. Hence, this natural experiment approach provides evidence that the bombings changed the voters' political views and induced voters to turnout in larger numbers. The change of political views in this case was a demand to reconsider international alliances, and the higher turnout arisen from the enhanced political engagement by citizens when the relevance of the policy dimension affected by the shock increased.

Overall, the literature provides strong arguments and substantial empirical evidence to support the claim that, shocks that induce changes in voters' preferences and the relative salience of issues do occur, and that they are exogenous to the actions of political parties. And therefore, they have major political consequences in re-aligning policy proposals and party systems.

\section{The model}

There are two parties, $A$ and $B$, that compete in an election. The policy space $\mathbf{X}$ is two dimensional and represented by the unit square $\mathbf{X}=[0,1] \times[0,1]$. Let $(x, y) \in X$ denote a policy position on each one of the issues. Before the election, parties simultaneously choose policy platforms $\left(x_{A}, y_{A}\right)$ and $\left(x_{B}, y_{B}\right)$ respectively from the policy space $\mathbf{X}$. Without loss of generality, we assume that there is a unique decisive voter who has preferences over policies represented by a utility function $u_{m}(x, y)=-\sigma\left(x-x_{m}\right)^{2}-(1-\sigma)\left(y-y_{m}\right)^{2}$ where $\left(x_{m}, y_{m}\right) \in X$ represents the voter's ideal policy and $\sigma \in\{0,1\}$ denotes the relative salience of issue $x$ over issue $y$.

We restrict the values of $\sigma$ to be only 0 or 1 because we are interested in the effect of a drastic change in the relevant policy dimension that is produced exogenously and that parties have to face unexpectedly. Values of $\sigma$ between 0 and 1 represent situations in which voters care about more than one issue at the time they decide their vote, and therefore they offer a scenario that is not the one that we intend to analyze.

Since we are interested in comparing the equilibrium policy choices before and after the shock, our set up allows us to perform an electoral competition equilibrium analysis in one dimension: parties compete only over issue y before the shock and parties compete only over issue $\mathrm{x}$ after the shock. This implies that for each one of the cases to be considered there is a single relevant voter: the median voter of the corresponding dimension. Before the shock the decisive voter corresponds to the voter with median ideal point in the y dimension and after the shock the decisive voter corresponds to the voter with the median ideal point in the $\mathrm{x}$ dimension.

We assume that parties do not know the exact location of $\left(x_{m}, y_{m}\right)$ and they have beliefs about it that are common knowledge and are represented by a probability distribution $F: \mathbf{X} \rightarrow[0,1]$ with support over $\mathbf{X}$ and with probability mass function $f: \mathbf{X} \rightarrow[0,1]$. 
Fig. 1 Polarized preferences

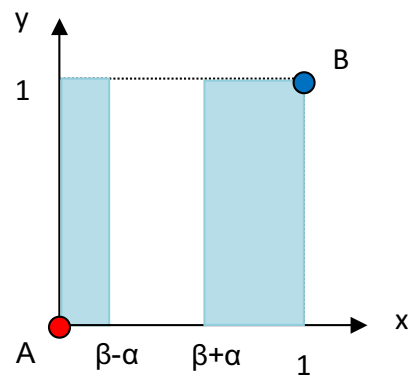

Since we are interested in the effects of a shock that increases the salience of an issue on which voters' preferences are polarized we assume that the beliefs of the parties about the location of the ideal point of the decisive voter are represented by $F(x, y)=F(x, y ; \alpha, \beta)$ where $F(x, y ; \alpha, \beta)$ denotes a uniform distribution over a support equal to $[0, \beta-\alpha] \cup[\alpha+\beta, 1]$ with $0 \leq \alpha<\beta \leq \frac{1}{2}$. Thus the parties' beliefs are represented by the following density function $f(x, y ; \alpha, \beta)=\left\{\begin{array}{clc}\frac{1}{1-2 \alpha} & \text { if } & 0 \leq x \leq \beta-\alpha \text { or } \alpha+\beta \leq x \leq 1 \\ 0 & \text { if } & \beta-\alpha<x<\alpha+\beta\end{array}\right.$

This function assigns positive probability of having a rather rightist voter, and positive probability of having a rather leftist voters, while it assigns zero probability to relative moderate positions. See Fig. 1. Parameter $\beta$ represents the magnitude of the bias of the distribution: when $\beta$ approaches $1 / 2$ the distribution becomes symmetric, and for small values of $\beta$ it becomes more likely that the voter's ideal point is on the right hand side of the policy space. Parameter $\alpha$ represents the magnitude of the polarization: when $\alpha$ approaches zero polarization disappears and the distribution becomes uniform over the whole policy space, and for larger values of $\alpha$ larger probabilities accumulate on the extremes of the policy space. Notice that when $\alpha$ approaches $\beta$ the distribution becomes completely biased to the right hand side of the policy space: it becomes a uniform distribution over the interval $[2 \beta, 1]$. Without loss of generality we assume that this bias always favors the most rightist policies by considering $\beta \leq \frac{1}{2}$. Finally, as both $\alpha$ and $\beta$ approach $\frac{1}{2}$ it becomes a degenerate distribution that assigns probability $\frac{1}{2}$ to each extreme of the policy space.

For every pair of policy choices $\left(x_{A}, x_{B}\right) \in X^{2}$ we have that the probability of win-

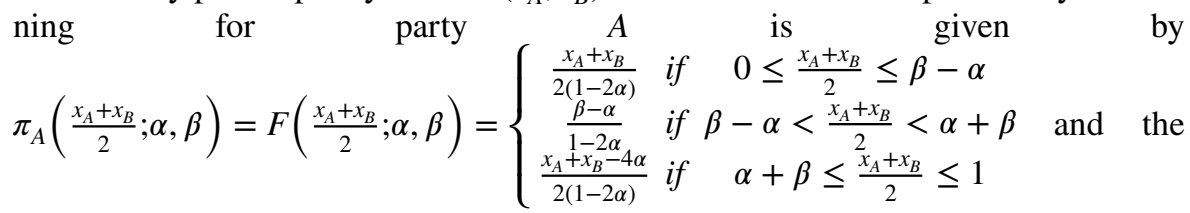
probability of winning for party $B$ is given by $\pi_{B}\left(x_{A}, x_{B} ; \alpha, \beta\right)=1-\pi_{A}\left(x_{A}, x_{B} ; \alpha, \beta\right)$.

Parties have policy preferences, just like voters. We assume that the ideal point of party $A$ is $(0,0)$ and the ideal point of party $B$ is $(1,1)$. The parties' ideal points are common knowledge. Parties are policy motivated and, their utility for policy platform $(x, y)$ is represented by $u_{A}(x, y)=-x^{2}-y^{2}$ and $u_{B}(x, y)=-(1-x)^{2}-(1-y)^{2}$ respectively. Each party maximizes his expected utility that is given by: 


$$
\begin{aligned}
& U_{A}\left(\left(x_{A}, y_{A}\right),\left(x_{B}, y_{B}\right)\right) \\
& \quad=\pi_{A}\left[-\left(x_{A}\right)^{2}-\left(y_{A}\right)^{2}\right]+\left(1-\pi_{A}\right)\left[-\left(x_{B}\right)^{2}-\left(y_{B}\right)^{2}\right] \\
& U_{B}\left(\left(x_{A}, y_{A}\right),\left(x_{B}, y_{B}\right)\right) \\
& \quad=\pi_{A}\left[-\left(1-x_{A}\right)^{2}-\left(1-y_{A}\right)^{2}\right]+\left(1-\pi_{A}\right)\left[-\left(1-x_{B}\right)^{2}-\left(1-y_{B}\right)^{2}\right]
\end{aligned}
$$

where $\pi_{A}=\pi_{A}\left(\left(x_{A}, y_{A}\right),\left(x_{B}, y_{B}\right)\right)$ denotes the probability of winning for party $A$ and $1-\pi_{A}$ denotes the probability of wining for party $B$ as a function of the parties' policy choices $\left(\left(x_{A}, y_{A}\right),\left(x_{B}, y_{B}\right)\right)$.

The game takes place in two stages. In the first stage, parties simultaneously choose positions in $\mathbf{X}$. We assume that parties implement their announced positions if they win the election. In the second stage, the decisive voter votes for the party whose election would give him the higher utility, if elected. In case of indifference, the voter is assumed to vote for each party with probability equal to $1 / 2$. Since the behavior of the voter is unambiguous in this model, we define an equilibrium of the game only in terms of the location strategies of the two parties in the first round.

Let $\left(\left(x_{A}, y_{A}\right),\left(x_{B}, y_{B}\right)\right) \in \mathbf{X}^{2}$ denote a pair of pure strategies for parties $A$ and $B$ respectively. We solve for the Nash equilibria of this game, that is, those pairs of pure strategies $\left(\left(x_{A}^{*}, y_{A}^{*}\right),\left(x_{B}^{*}, y_{B}^{*}\right)\right) \in \mathbf{X}^{2}$ such that

$$
\begin{aligned}
& U_{A}\left(\left(x_{A}^{*}, y_{A}^{*}\right),\left(x_{B}^{*}, y_{B}^{*}\right)\right) \geq U_{A}\left(\left(x_{A}, y_{A}\right),\left(x_{B}^{*}, y_{B}^{*}\right)\right) \text { for all }\left(x_{A}, y_{A}\right) \in \mathbf{X} \text { and } \\
& U_{B}\left(\left(x_{A}^{*}, y_{A}^{*}\right),\left(x_{B}^{*}, y_{B}^{*}\right)\right) \geq U_{B}\left(\left(x_{A}^{*}, y_{A}^{*}\right),\left(x_{B}, y_{B}\right)\right) \text { for all }\left(x_{B}, y_{B}\right) \in \mathbf{X} .
\end{aligned}
$$

\section{Effects of a shock on the relative issue salience}

We study the effects of a shock that produces a change on the relative salience of the two issues in a particular way: the salient issue before the shock is one in which in the voter's preferences are distributed uniformly and the salient issue after the shock is one in which the voters' preferences are polarized. In terms of the model described above, the effects of the shock are represented by a change in the value of the parameter $\sigma$ which describes the relative salience of the two issues. We assume that the value of $\sigma$ before the shock is 0 . This implies that before the shock the salient issue is $y$, and thus this is the only issue that voters take into account when deciding their vote before the shock. We assume that the value of $\sigma$ after the shock is 1 . This implies that after the shock the salient issue is $x$, and thus this is the only issue that voters take into account when deciding their vote after the shock.

We compare the equilibrium policy choices before and after the shock, and thus this set up allows us to perform an electoral competition equilibrium analysis in one dimension: parties compete only on the y dimension before the shock and parties compete only on the $\mathrm{x}$ dimension after the shock. This implies that for each set up analyzed there is a single relevant voter: the median voter of the corresponding dimension. Before the shock the decisive voter corresponds to the voter with median ideal point in the y dimension and after the shock the decisive voter corresponds to the voter with the median ideal point in the $\mathrm{x}$ dimension. 
First, we describe the equilibrium results in the absence of any shock.

Proposition 1 If $\sigma=0$ the parties' equilibrium strategies are $\left(x_{A}^{*}(0), y_{A}^{*}(0)\right)=\left(0, \frac{1}{4}\right)$ and $\left(x_{B}^{*}(0), y_{B}^{*}(0)\right)=\left(1, \frac{3}{4}\right)$.

All proofs are relegated to the appendix

Before the shock, issue $y$ is infinitely more salient than issue $x$, thus the voting decision is only affected by the parties' positions on issue $y$. In this case, since parties are policy motivated, their optimal choices on the non salient issue coincide with their ideal points. Since the distribution of the voters' preferences on the salient issue are uniform, on this issue parties are going to moderate their policy choices in a symmetric way, by choosing platforms halfway between their respective ideal points and the expected median voter's ideal point.

This case is a direct application of the model of two party competition with policy motivated parties described in Calvert (1985) and Wittman (1977, 1983). Both parties moderate their policies in a symmetric way, by choosing platforms halfway between their respective ideal points and the expected median voter's ideal point, and they both win with equal probability. This result describes the parties' optimal policy choices before the shock takes place.

Now we introduce a preference shock that affects the relative issue salience. Notice that as the value of the parameter that represents the relative issue salience increases, issue $x$ becomes more salient, and the voting decision is conditioned by the policy choices of the parties on both issues. As the value of $\sigma$ increases the voting decision shifts weights between issues: the utility that voters derive from policies implemented on issue $x$ becomes more important, and more relevant to decide to whom to give their vote, and this forces parties to moderate their positions also on that issue. Thus if the shock affects the voters' relative issue salience, after the shock parties will choose a moderate policy position on the issue that has become salient due to the shock. The next result describes the equilibrium results after the shock is produced.

Proposition 2 If $\sigma=1$ the parties' equilibrium strategies for $\beta \geq \bar{\beta}(\alpha)$ are $\left(x_{A}^{*}(1), y_{A}^{*}(1) Z_{Z}=(0,0)\right.$ and $\left(x_{B}^{*}(1), y_{B}^{*}(1)\right)=(1,1)$ and the parties' equilibrium strategies for $\beta \leq \bar{\beta}(\alpha)$ are

$$
\left(x_{A}^{*}(1), y_{A}^{*}(1)\right)=\left(3 \frac{5+3 \alpha+\sqrt{9 \alpha^{2}-2 \alpha+1}}{8}-2,0\right)
$$

and

$$
\left(x_{B}^{*}(1), y_{B}^{*}(1)\right)=\left(\frac{5+3 \alpha+\sqrt{9 \alpha^{2}-2 \alpha+1}}{8}, 1\right)
$$

This proposition characterizes two different types of equilibrium strategies. One in which the two parties diverge completely by implementing their ideal points, and another one in which the two parties partially converge. See Figs. 2 and 3. The 

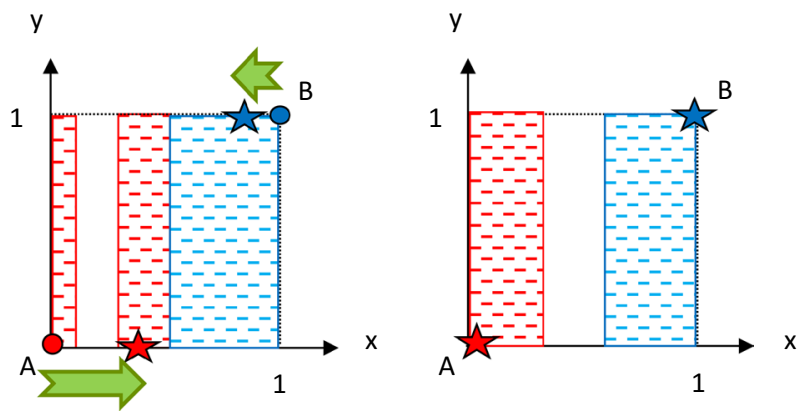

Fig. 2 Effect of the shock for polarized preferences

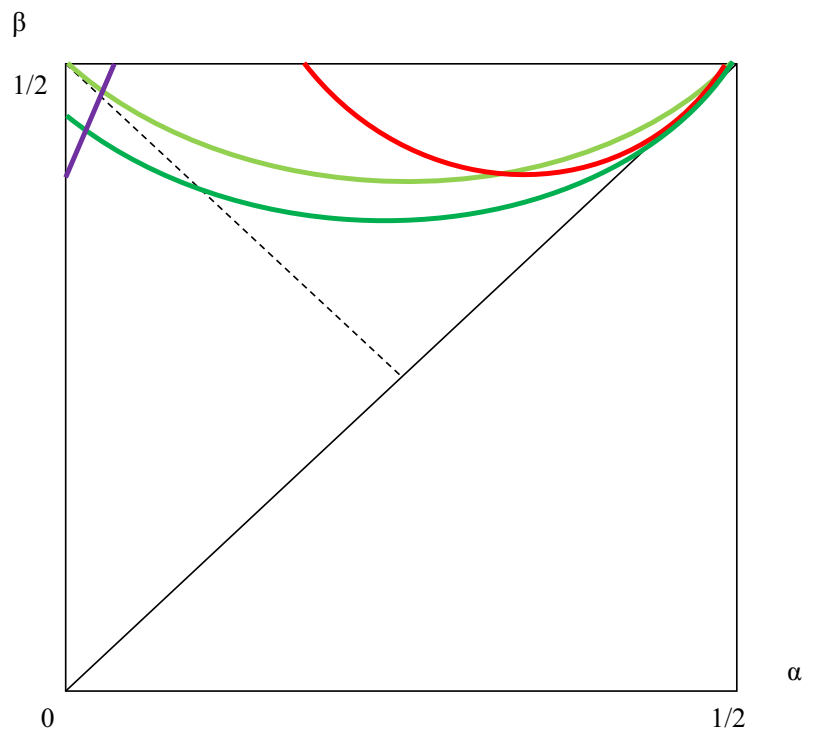

Fig. 3 Above the red line, extreme equilibrium strategies. Below the purple and dark green lines, interior equilibrium strategies

magnitude of the bias of the distribution of the voters' preferences, represented by the parameter $\beta$, determines which equilibrium holds. The values of the two cutoffs $\bar{\beta}(\alpha)$ and $\bar{\beta}(\alpha)$ are described in the appendix. Notice that since $\bar{\beta}(\alpha)>\bar{\beta}(\alpha)$ we have that the two sets of parameter values for which each one of these equilibria exist do not intersect, therefore we have uniqueness of equilibrium in each one of these sets of parameter values. Otherwise, for values of $\beta$ that lie between the two cutoffs there is no equilibrium in pure strategies.

The equilibrium with extreme strategies exists whenever the values of both $\alpha$ and $\beta$ are relatively large, that is, whenever the distribution of the voters' ideal points is very polarized but not too biased. This case can be illustrated by a population 
consisting of two large groups of very extremist voters, that induces parties to choose extreme policies because the possible policy deviations that may increase their expected vote shares are so far away from their ideal points that are not profitable.

When the distribution of the voters' ideal points is more biased, that is, for smaller values of $\beta$, the extreme strategies are no longer an equilibrium. In this case, one of the parties, party $B$ in our case, enjoys an advantage because the proportion of rightist voters is much larger than the proportion of leftist voters. In this case, the disadvantaged party, party $A$, has a strong incentive to moderate his position in order to increase his vote share beyond the group of his close supporters. This induces party $B$ to moderate his position in order to defend his close supporters. Therefore in this case we obtain an interior equilibrium in which both parties are partially converging and the policy shift produced by party $\mathrm{A}$ is much larger than the shift produced by party B.

Notice that the strategies of both parties in this interior equilibrium depend only on the value of the parameter $\alpha$. Thus the degree of convergence of the parties' strategies is determined solely by the degree of polarization of the voters' preferences whenever the interior equilibrium exists. Notice that the degree of polarization is a measure of the support of the distribution of the voters' preferences: the more polarized, the smaller the support. However the set of parameter values that guarantee the existence of the interior equilibrium is determined by the combination of the values of both the polarization and the bias of the distribution: when the bias of the distribution is not too large and the support of the distribution is not too small. Otherwise, if the support of the distribution is small, which implies that voters' ideal points are concentrated in the extremes of the policy space, then in equilibrium parties diverge choosing their ideal points.

Observe that in this interior equilibrium the strategies of both parties become more rightist whenever $\alpha$ increases, because for a given distribution bias, when polarization increases party $A$ has to choose a more aggressive strategy and thus party $B$ can optimally relax his response. If instead we consider the case of $\alpha=0$ we find a direct application of the model of two party competition with policy motivated parties described in Calvert (1985) and Wittman (1977 and 1983) in which $x_{A}^{*}=\frac{1}{4}$ and $x_{B}^{*}=\frac{3}{4}$, that is, both parties moderate their policies in a symmetric way, by choosing platforms halfway between their respective ideal points and the expected median voter's ideal point, and they both win with equal probability.

Notice that the policies chosen in equilibrium by the two parties are located on both sides of the expected ideal point of the decisive voter. Even though party A produces a larger move towards the expected ideal point of the decisive voter than party B, in equilibrium party B's policy choice ends up being much closer to the expected ideal point of the decisive voter than party A's. For larger values of $\alpha$ both parties' policy choices move towards the right side of the policy space, closer to each other.

In equilibrium the probability of winning for party $\mathrm{A}$ is always smaller than the probability of winning for party B. The policy shift produced by party A moving away from his ideal point is much larger than the shift produced by party B. Thus, party $\mathrm{A}$ is clearly the disadvantaged party and its expected payoffs in equilibrium are smaller than those of party B. 
Fig. 4 Density function for $\alpha=\beta$

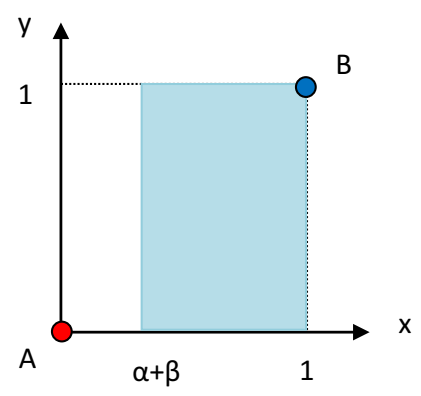

Whenever neither of the conditions described in the proposition holds we do not have existence of pure strategy equilibrium. This is the case when large values of $\beta$ coexist with small values of $\alpha$, that is, when the distribution is rather symmetric and not very polarized. Both parties choosing their ideal points cannot be an equilibrium, because the disadvantaged party would have an incentive to moderate his position and increase his probability of winning. The internal equilibrium does not hold because given that party $\mathrm{B}$ is choosing a moderate position and polarization is low party $\mathrm{A}$ is better off securing his group of supports with a leftist policy. Thus for large values of $\beta$ and small values of $\alpha$ only mixed strategy equilibrium exists, and its characterization is beyond the scope of this paper.

We complete our analysis considering the particular case in which $\alpha=\beta$. In this case, the value of the polarization parameter coincides exactly with the value of the parameter that determines the bias. This implies that the final distribution of the voters' preferences is not divided in two different and opposed segments, instead it becomes a distribution that is completely biased towards one side of the policy space with respect to the $\mathrm{x}$ dimension. Following the previous analysis we assume without loss of generality that the distribution is biased towards the right side of the policy space. See Fig. 4.

In this case we have that the beliefs of the parties on the expected location of the median voter's ideal point are represented by $F(x, y)=F(x, y ; \alpha)$ where $F(x, y ; \alpha)$ denotes a uniform distribution over a support equal to [2 $\alpha, 1]$ with $0 \leq \alpha<\frac{1}{2}$. Thus the parties' beliefs are represented by the following density function $f(x, y ; \alpha)=\left\{\begin{array}{cll}\frac{1}{1-2 \alpha} & \text { if } & 2 \alpha \leq x \leq 1 \\ 0 & \text { if } & 0 \leq x<2 \alpha\end{array}\right.$

As before we will have that since the shock affects the voters' relative issue salience, after the shock parties will choose moderate policy position on the issue that has become salient due to the shock. Notice that as before party A suffers a disadvantage from the voters' preference policy shift, because voters' ideal points are further away from party A's ideal point, while party B obtains a strategic advantage since voters' ideal points are closer to party B's ideal point. The next result describes the equilibrium results after the shock is produced.

\section{Proposition 3 If $\sigma=1$ then the parties' equilibrium strategies are}


Fig. 5 Effect of the shock for biased preferences

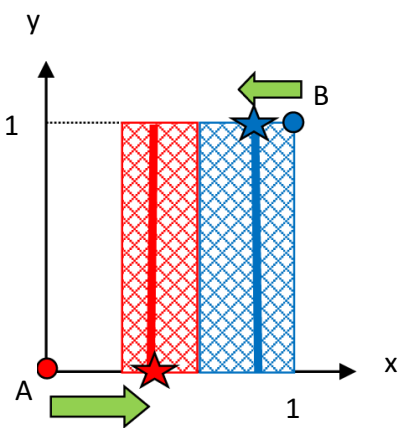

$$
\left(x_{A}^{*}(\alpha), y_{A}^{*}(\alpha)\right)=\left(\frac{18 \alpha-2+\sqrt{(2-18 \alpha)^{2}+32}}{16}, 0\right)
$$

and

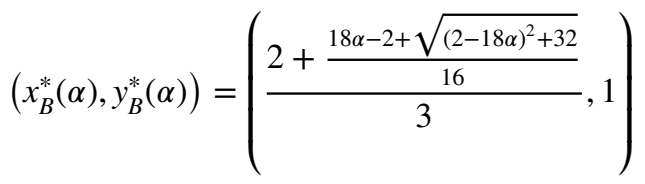

This result shows once more that after the shock the parties' policy choices in equilibrium are conditioned on the value of the parameter that represents the intensity of the shock, $\alpha$. Figure 5 represents graphically the parties' policy choices on the two dimensional policy space. Since $x$ has become the most salient issue after the shock, voters will base their decision only on the parties' policy choices on issue $x$. Thus parties have to moderate their positions on issue $x$ exactly as if they were competing on a one dimensional model, and they can propose their ideal points on the non-salient issue $y$.

In order to compare the equilibrium policy choices before and after the shock we have to compare the equilibrium policy choices corresponding to $\sigma=0$ with those corresponding to $\sigma=1$. Since after the shock issue $y$ becomes irrelevant in terms of the voting decision, parties are going to reverse their symmetric and moderate policy choices to their ideal points on that issue, and they will abandon their ideal points on the new salient issue and choose instead moderate policies in an asymmetric way: party A is forced to more moderate policies because of its electoral disadvantage. As before, the overall effect of the shock is determined by the distance from the policies chosen by the parties in equilibrium to their corresponding ideal points, which are the policies chosen in the y dimension in the absence of the shock. 


\section{Party consequences of a large policy shift}

Our analysis shows that a preference shock forces one of the parties to a large change on his policy position away from its ideal point. Since parties' internal consistency is based on a balance between the different ideological positions of the different factions, it is plausible to think that the need for such sudden policy change might affect the equilibrium of forces inside a party, and might break up the stability of party systems.

In order to illustrate this phenomenon we review recent events in Catalonia and the UK where a sudden boost in the relative salience of an issue has imposed the need to make major adjustments in the policy proposals of the dominant parties and this has affected the stability of the party system.

Catalonia has recently experienced drastic changes in a party system that was stable for over 30 years. The Catalan political debate has always been spread over two policy dimensions: the ideological or economic dimension and the sovereignty or decentralization dimension. Until the first decade of the twenty first century political preferences of the Catalan society on the economic dimension covered most of its range: from extreme right to extreme left. However on the sovereignty dimension political preferences were rather moderate. There were claims for different moderate degrees of decentralization but on the extremes these claims were very weak: demands for policies close to full centralization or to full independence were supported by a very small part of the population. Accordingly, the policy positions of the political parties over these two issues were moderate on the sovereignty issue and covered the full range of policies on the economic issue.

From 1980 up until 2010 the Catalan party system appeared as a stable system that contained five political parties. Convergència i Unió (CIU), a Catalan centerright coalition that stood for increasing decentralization had the largest electoral support. Partit Socialista de Catalunya (PSC), a Catalan center-left party that supported different decentralization claims over time was the second largest party. Two other parties had much smaller electoral supports, but they played significant roles in the governing coalitions that formed during the period: a Spanish rightist and centralist party, Partido Popular (PP) and a Catalan leftist and independentist party, Esquerra Republicana de Catalunya (ERC). Finally, Iniciativa per Catalunya-Verds (ICV) a leftist green party that mildly stood for decentralization had the smallest electoral support.

The possibilities of majoritarian coalitions involved all kinds of cross ideological agreements among parties on both issues ${ }^{1}$. However, we only observe two kinds of governments: those supported by rightist parties (CIU and PP) and those supported by leftist parties (PSC, ERC, and ICV). There was never a government formed or supported by parties that shared the same political views on the sovereignty issue. This observation leads us to conclude that it was more costly for political parties to compromise their positions on the economic issue than on the sovereignty issue.

\footnotetext{
${ }^{1}$ For a detailed analysis of the governments formed during this period in Catalonia see Aragones (2007).
} 
The implication of this observation is that the salience of the sovereignty issue was clearly dominated by the salience of the economic issue during this period.

Things changed after 2010, when the Spanish Constitutional Court ruled to dismiss the reform of the Catalan self-government charter (which had been approved with a very strong consensus in 2005). This ruling of the Spanish high court has played a the role of a focusing event that has greatly switched the attention of the Catalan voters to the sovereignty dimension, and has induced a notable change in the political preferences of the Catalan electorate. While Catalan independence was supported only by a minority of about 10-15 percent from 1980 until 2009, this support experienced a very sharp increase to values right after the after the Constitutional Court ruling, and has since then consistently exhibited supports close to 50 percent in polls and electoral results ${ }^{2}$. This implies that on the one hand, the relevant policy space that parties must cover has been enlarged: it includes extreme decentralization positions that are supported by increasing number of voters. And on the other hand, the relative salience of the two issues has changed dramatically with the sovereignty issue becoming much more salient than the economic issue.

At the same time three new parties entered the political area. Ciudadanos (C) claims no position on the economic issue but a strong position on the sovereignty issue advocating for extreme centralization. Candidatura d'Unitat Popular (CUP) has a strong independentist and leftist position. And finally Podemos (P) holds a strong leftist position and a moderate position on the sovereignty issue.

Parties' policy positions had to adapt to the new political environment. It is interesting to notice how different parties have used very different strategies to deal with the new preferences of the constituency. ${ }^{3}$ On the one hand, we observe that a few parties have adapted in a very easy and natural way: some of them by not moving from their initial positions (C, PP, CUP, P, ICV) and others by reverting their compromised moderate policies to their original ideal points (ERC, originally defined as independentist). However, the two largest parties have had a harder time to adapt to the new environment. PSC suffered severe internal party tensions that drove it to break into several small factions with leftist-independentist positions and a somewhat larger faction holding a leftist-centralist position. Similarly, CIU also broke into several small factions holding different positions on the sovereignity issue and a larger faction with a rightist-independentist position. Thus, the effect of a voters' preference shock was mostly suffered by the two largest parties, which were parties that had to support a more complicated and perhaps fragile internal equilibrium of forces. The breakdown of the two major parties into different factions produced a drastic change in the existing Catalan party system.

In the UK, the Brexit referendum brought about another shock causing a major upheaval in voters' political preferences and the political party system. While ambivalence regarding membership in the EU has been a constant in British politics,

\footnotetext{
${ }^{2}$ For a detailed analysis of the evolution of the political preferences in Catalonia during this period see Guinjoan and Rodon (2016).

${ }^{3}$ For a detailed analysis of the evolution of the Catalan party system during this period see Aragones and Ponsati (2016).
} 
this was not a major subject in the electoral competition until David Cameron prior to June 2016. After the referendum delivered its unexpected majority for Brexit, membership in the EU has become the salient issue in the political debate. Both the Conservative and Labour parties, having campaigned on both sides of the question, faced the imperative need to clarify their proposals deeply divided. The minor Brexit party and the LibDems, with clear views in favor and against Brexit, have become a major threat to the two big parties under the new scenario. Tories have adjusted to extreme Brexit positions, while Labor remains diffident.

In Scotland, where a large majority opposed Brexit, the shock has boosted the salience of the independence-union debate, greatly benefiting the agenda of the Scottish National Party. In Wales opposition to Brexit has also increased support to Plaid Cymru. Reunification may gain support in Northern Ireland if Brexit reestablished the border breaking the good Friday agreements. What the British political landscape will look like after the present crisis, and wether the UK will survive it, are still very open questions.

\section{Concluding remarks}

We have argued that exogenous shocks change voters' policy preferences and demand policy adjustments by the political parties. When these shocks occur they have important implications on the survival of political parties. The polarization of the voters' political preferences caused by the shock induces parties to react in an asymmetric way, because while one party gains from the shock the other party suffers a disadvantage. The change in the relative salience of issues due to the shock induces parties to moderate their policies on an issue in which they could have otherwise implemented their ideal policies, because as in Ansolabehere and Puy (2018) parties are not interested in competing on issues that are not relevant for the voters. The overall effect of a shock forces one of the parties, the disadvantaged one, to produce a large policy shift on the issue hit by the shock. We have illustrated how such a drastic policy change may destroy the internal consistency of the party.

The analysis presented relies on several assumptions. In particular, we assume that parties' ideal points are not affected by the shock. This is a point that can hardly be proved nor disproved by empirical evidence. If they were assumed to be affected by the shock in the same way than voters' preferences are, then none of the results presented would hold. However, if they were assumed to be less affected by the shock than voters' preferences are, then the results would be qualitatively the same.

We have assumed that parties' utility functions are quadratic. If they were assumed to be linear the results would not be as interesting, since in this case we have that some equilibrium policies deliver corner solutions, and thus the comparative statics analysis of the shock would not be as rich as the one provided by concave utility functions. Parties with quadratic utility functions suffer great loses from policies that are far away for their ideal point, thus they tend to moderate their policy positions but not to the point of converging to the ideal point of the median voter.

We have also assumed that parties are policy motivated. If parties were only office motivated, as in a standard model a la Downs (1957) then in equilibrium 
they would both always converge to the ideal point of the current expected median of the dimension that is salient. Thus, the qualitative results of moderate policies and asymmetric reactions would still hold in this case. If instead parties were assumed to be both policy and office motivated, then the results presented here would be slightly modified by the fact that in this case both parties will have stronger incentives to moderate their policy choices.

Finally, we have assumed that parties assign the same weight to the utility losses produced on all issues, that is, all issues are considered equally salient and their relative issue salience is not affected by the shock. We think that these are reasonable assumptions since on the one hand a party represents an aggregated pool of different sensitivities and ideological views, and thus it is plausible to assume that in general it would suffer a similar utility cost from any policy loss on any issue. And, on the other hand, voters' sensitivity is probably more likely to be affected by a shock, and thus voters are going to react more intensively to a preference shock. However, it would be interesting to see how results might change if these assumptions were relaxed.

\section{Appendix}

Proof of proposition 1 If $\sigma=1$ and $\alpha=0$ then the decisive voter's utility function is given by:

$$
u_{m}(x, y)=-\sigma\left(x-x_{m}\right)^{2}-(1-\sigma)\left(y-y_{m}\right)^{2}=-\left(x-x_{m}\right)^{2}
$$

The problem is unidimensional. The parties' optimization problem contains no restrictions on the $y$ dimension, therefore they can implement their ideal points on this dimension with no electoral cost.

With respect to the $x$ dimension for every pair of policy choices $\left(x_{A}, x_{B}\right) \in X^{2}$ we have that the probability of winning for party $A$ is given by $\pi_{A}\left(x_{A}, x_{B}\right)=\frac{x_{A}+x_{B}}{2}$ and the probability of winning for party $B$ is given by $\pi_{B}\left(x_{A}, x_{B}\right)=1-\pi_{A}\left(x_{A}, x_{B}\right) \stackrel{2}{=} 1-\frac{x_{A}+x_{B}}{2}$

Parties' payoffs functions can be written as

$$
\begin{aligned}
U_{A}\left(x_{A}, x_{B}\right) & =-\frac{x_{A}+x_{B}}{2}\left(x_{A}\right)^{2}-\left[1-\frac{x_{A}+x_{B}}{2}\right]\left(x_{B}\right)^{2} \\
& =\frac{x_{A}+x_{B}}{2}\left[-\left(x_{A}\right)^{2}+\left(x_{B}\right)^{2}\right]-\left(x_{B}\right)^{2} \\
U_{B}\left(x_{A}, x_{B}\right) & =-\frac{x_{A}+x_{B}}{2}\left(1-x_{A}\right)^{2}-\left[1-\frac{x_{A}+x_{B}}{2}\right]\left(1-x_{B}\right)^{2} \\
& =\frac{x_{A}+x_{B}}{2}\left[\left(1-x_{B}\right)^{2}-\left(1-x_{A}\right)^{2}\right]-\left(1-x_{B}\right)^{2}
\end{aligned}
$$

The first order conditions are: 


$$
\begin{aligned}
& \frac{\partial U_{A}\left(x_{A}, x_{B}\right)}{\partial x_{A}}=\frac{-\left(x_{A}\right)^{2}+\left(x_{B}\right)^{2}}{2}-\frac{x_{A}+x_{B}}{2} 2 x_{A}=0 \\
& \frac{\partial U_{B}\left(x_{A}, x_{B}\right)}{\partial x_{B}}=\frac{\left(1-x_{B}\right)^{2}-\left(1-x_{A}\right)^{2}}{2}-\frac{x_{A}+x_{B}}{2} 2\left(1-x_{B}\right)+2\left(1-x_{B}\right)=0
\end{aligned}
$$

which imply that their reaction functions are:

$$
\begin{aligned}
& x_{A}\left(x_{B}\right)=\frac{x_{B}}{3} \\
& x_{B}\left(x_{A}\right)=\frac{2+x_{A}}{3}
\end{aligned}
$$

The second order conditions are:

$$
\begin{gathered}
\frac{\partial^{2} U_{A}\left(x_{A}, x_{B}\right)}{\partial\left(x_{A}\right)^{2}}=-3 x_{A}-x_{B}<0 \\
\frac{\partial^{2} U_{B}\left(x_{A}, x_{B}\right)}{\partial\left(x_{B}\right)^{2}}=x_{A}+3 x_{B}-4<0
\end{gathered}
$$

Thus in equilibrium we must have: $x_{A}=\frac{1}{4}$ and $x_{B}=\frac{3}{4} \quad$ with $x_{A}<x_{B}, x_{A}+x_{B}=1, x_{A}-x_{B}=1 / 2$, and $U_{A}\left(x_{A}, x_{B}\right)=U_{B}\left(x_{A}, x_{B}\right)=-\frac{5}{16}$.

Therefore, the parties' equilibrium strategies are given by $\left(x_{A}^{*}(0), y_{A}^{*}(0)\right)=\left(\frac{1}{4}, 0\right)$ and $\left(x_{B}^{*}(0), y_{B}^{*}(0)\right)=\left(\frac{3}{4}, 1\right)$

Proof of Proposition 2 If $f(x ; \alpha, \beta)=\left\{\begin{array}{clc}\frac{1}{1-2 \alpha} & \text { if } & 0 \leq x \leq \beta-\alpha \text { or } \alpha+\beta \leq x \leq 1 \\ 0 & \text { if } & \beta-\alpha \leq x \leq \alpha+\beta\end{array}\right.$ for every pair of policy choices $\left(x_{A}, x_{B}\right) \in X^{2}$ with $x_{A} \leq x_{B}$ we have that the probability of winning for party $A$ is given by $\begin{aligned} \pi_{A}\left(\frac{x_{A}+x_{B}}{2} ; \alpha, \beta\right)=F\left(\frac{x_{A}+x_{B}}{2} ; \alpha, \beta\right) & =\left\{\begin{array}{ccc}\text { warty } & A & \text { given } \\ \frac{x_{A}+x_{B}}{2(1-2 \alpha)} & \text { if } & 0 \leq \frac{x_{A}+x_{B}}{2} \leq \beta-\alpha \\ \frac{\beta-\alpha}{1-2 \alpha} & \text { if } & \beta-\alpha \leq \frac{x_{A}+x_{B}}{2} \leq \alpha+\beta \text { with } \\ \frac{x_{A}+x_{B}-4 \alpha}{2(1-2 \alpha)} & \text { if } & \alpha+\beta \leq \frac{x_{A}+x_{B}}{2} \leq 1\end{array}\right. \\ \frac{\partial \pi_{A}}{\partial x_{A}}\left(\frac{x_{A}+x_{B}}{2} ; \alpha, \beta\right) & =\left\{\begin{array}{ccc}0 & \text { if } & \beta-\alpha \leq \frac{x_{A}+x_{B}}{2} \leq \alpha+\beta \\ \frac{1}{2(1-2 \alpha)} & \text { otherwise }\end{array}\right.\end{aligned}$ and $\frac{\partial^{2} \pi_{A}}{\partial\left(x_{A}\right)^{2}}\left(\frac{x_{A}+x_{B}}{2} ; \alpha, \beta\right)=0$ 
And the probability of winning for party $B$ is given by $\pi_{B}\left(x_{A}, x_{B} ; \alpha, \beta\right)=1-\pi_{A}\left(x_{A}, x_{B} ; \alpha, \beta\right)$.

The parties' payoffs functions and their first and second order conditions are given by:

$$
\begin{aligned}
& U_{A}\left(x_{A}, x_{B} ; \alpha, \beta\right)=\pi_{A}\left(\frac{x_{A}+x_{B}}{2} ; \alpha, \beta\right)\left[\left(x_{B}\right)^{2}-\left(x_{A}\right)^{2}\right]-\left(x_{B}\right)^{2} \\
& \frac{\partial U_{A}}{\partial x_{A}}\left(x_{A}, x_{B} ; \alpha, \beta\right)=\frac{\partial \pi_{A}}{\partial x_{A}}\left[\left(x_{B}\right)^{2}-\left(x_{A}\right)^{2}\right]-2 x_{A} \pi_{A}\left(\frac{x_{A}+x_{B}}{2} ; \alpha, \beta\right)=0 \\
& \frac{\partial^{2} U_{A}}{\partial\left(x_{A}\right)^{2}}\left(x_{A}, x_{B} ; \alpha, \beta\right)=-4 x_{A} \frac{\partial \pi_{A}}{\partial x_{A}}-2 \pi_{A}\left(\frac{x_{A}+x_{B}}{2} ; \alpha, \beta\right) \leq 0 \\
& U_{B}\left(x_{A}, x_{B} ; \alpha, \beta\right)=\pi_{A}\left(\frac{x_{A}+x_{B}}{2} ; \alpha, \beta\right)\left[\left(1-x_{B}\right)^{2}-\left(1-x_{A}\right)^{2}\right]-\left(1-x_{B}\right)^{2} \\
& \frac{\partial U_{B}}{\partial x_{B}}\left(x_{A}, x_{B} ; \alpha, \beta\right)=\frac{\partial \pi_{A}}{\partial x_{B}}\left[\left(1-x_{B}\right)^{2}-\left(1-x_{A}\right)^{2}\right] \\
& \quad+2\left(1-x_{B}\right)\left[1-\pi_{A}\left(\frac{x_{A}+x_{B}}{2} ; \alpha, \beta\right)\right]=0 \\
& \frac{\partial^{2} U_{B}}{\partial\left(x_{B}\right)^{2}}\left(x_{A}, x_{B} ; \alpha, \beta\right)=-4\left(1-x_{B}\right) \frac{\partial \pi_{A}}{\partial x_{B}}-2\left[1-\pi_{A}\left(\frac{x_{A}+x_{B}}{2} ; \alpha, \beta\right)\right] \leq 0
\end{aligned}
$$

Notice that since we have $\frac{\partial \pi_{A}}{\partial x_{A}}, \frac{\partial \pi_{A}}{\partial x_{B}} \geq 0$, the second order conditions are always satisfied. In order to compute the equilibrium policy choices we have to consider three cases:

a) those $\left(x_{A}, x_{B}\right)$ such that $\frac{x_{A}+x_{B}}{x^{2} x_{B}} \in[0, \beta-\alpha]$,

b) those $\left(x_{A}, x_{B}\right)$ such that $\frac{x_{A} 2 x_{B}}{x^{2} x_{B}} \in[\beta-\alpha, \beta+\alpha]$,

c) those $\left(x_{A}, x_{B}\right)$ such that $\frac{x_{A} 2 x_{B}}{2} \in[\beta+\alpha, 1]$,

First suppose that we are in case a) thus we have that $\left(x_{A}, x_{B}\right)$ are such that $\frac{x_{A}+x_{B}}{2} \in[0, \beta-\alpha]$. In this case, the probability of winning for party $A$ is given by $\pi_{A}\left(\frac{x_{A}+x_{B}}{2} ; \alpha, \beta\right)=\frac{x_{A}+x_{B}}{2(1-2 \alpha)}$ and the first order condition for party $A$ is $\left[\left(x_{B}\right)^{2}-\left(x_{A}\right)^{2}\right]-2 x_{A}\left(x_{A}+x_{B}\right)=0$ which holds if and only if $\left[x_{B}-3 x_{A}\right]\left(x_{A}+x_{B}\right)=0$ thus the best response of party $A$ in this case is given by $B R_{A}\left(x_{B}\right)=\frac{x_{B}}{3}$. Notice that $B R_{A}\left(x_{B}\right) \geq 0, B R_{A}\left(x_{B}\right) \leq x_{B}$. The first order condition for 
party $B$ is $\left(1-x_{A}\right)^{2}-\left(1-x_{B}\right)^{2}=2\left(1-x_{B}\right)\left[2(1-2 \alpha)-\left(x_{A}+x_{B}\right)\right]$ which holds if and only if

$$
x_{B}=\frac{4(1-\alpha)-x_{A} \pm \sqrt{\left[4(1-\alpha)-x_{A}\right]^{2}+3\left(\left(x_{A}\right)^{2}-4(1-2 \alpha)\right)}}{3}
$$

Notice that $\frac{4(1-\alpha)-x_{A}+\sqrt{\left[4(1-\alpha)-x_{A}\right]^{2}+3\left(\left(x_{A}\right)^{2}-4(1-2 \alpha)\right)}}{3}>1$ thus $B R_{B}\left(x_{A}\right)=$ $\frac{4(1-\alpha)-x_{A}-\sqrt{\left[4(1-\alpha)-x_{A}\right]^{2}+3\left(\left(x_{A}\right)^{2}-4(1-2 \alpha)\right)}}{3}$

Notice that $B R_{B}\left(x_{A}\right) \leq 1$ always, and $B R_{B}\left(x_{A}\right) \geq x_{A}$ if and only if $x_{A} \leq 1-2 \alpha$.

Thus for $\frac{x_{A}+x_{B}}{2} \in[0, \beta-\alpha]$ the equilibrium candidates have to satisfy $x_{A}=\frac{x_{B}}{3}$ and

$$
\begin{gathered}
x_{B}=\frac{4(1-\alpha)-x_{A}-\sqrt{\left[4(1-\alpha)-x_{A}\right]^{2}+3\left(\left(x_{A}\right)^{2}-4(1-2 \alpha)\right)}}{3} \text {, which implies that } \\
x_{A}=\frac{3(1-\alpha) \pm \sqrt{9 \alpha^{2}-2 \alpha+1}}{8} .
\end{gathered}
$$

Notice that in this case we need to satisfy $\frac{x_{A}+x_{B}}{2}=2 x_{A}<\beta-\alpha$ and this holds if and only if $\beta>\frac{3(1-\alpha) \pm \sqrt{9 \alpha^{2}-2 \alpha+1}}{4}+\alpha$. Since $\frac{3(1-\alpha) \pm \sqrt{9 \alpha^{2}-2 \alpha+1}}{4}+\alpha>\frac{1}{2}$ for all $\alpha<\frac{1}{2}$ and we have assumed that $\beta<\frac{1}{2}$, we cannot have an equilibrium in this case.

Next suppose that we are in case b) thus we have that $\left(x_{A}, x_{B}\right)$ are such that $\frac{x_{A}+x_{B}}{2} \in[\beta-\alpha, \beta+\alpha]$. In this case, the probability of winning for party $A$ is given by $\pi_{A}\left(\frac{x_{A}+x_{B}}{2} ; \alpha, \beta\right)=\frac{\beta-\alpha}{1-2 \alpha}$ and we have that $\frac{\partial U_{A}}{\partial x_{A}}<0$. Thus the best response for party $A$ in this case is:

$$
\begin{gathered}
B R_{A}\left(x_{B}\right)=\min \left\{x_{A}: \beta-\alpha \leq \frac{x_{A}+x_{B}}{2}\right\} \\
=\left\{\begin{array}{cl}
0 & \text { if } 2(\beta-\alpha) \leq x_{B} \\
2(\beta-\alpha)-x_{B} & \text { if } 2(\beta-\alpha) \geq x_{B}
\end{array}\right.
\end{gathered}
$$

Notice that $B R_{A}\left(x_{B}\right) \geq 0$, and $B R_{A}\left(x_{B}\right) \leq x_{B}$ iff $\beta-\alpha \leq x_{B}$.

Similarly we have that $\frac{\partial U_{B}}{\partial x_{B}}>0$. Thus the best response for party $B$ in this case is:

$$
\begin{array}{r}
B R_{B}\left(x_{A}\right)=\max \left\{x_{B}: \frac{x_{A}+x_{B}}{2} \leq \alpha+\beta\right\} \\
=\left\{\begin{array}{cl}
2(\beta+\alpha)-x_{A} & \text { if } 2(\beta+\alpha)-1 \leq x_{A} \\
1 & \text { if } 2(\beta+\alpha)-1 \geq x_{A}
\end{array}\right.
\end{array}
$$

Notice that $B R_{B}\left(x_{A}\right) \leq 1$ and $B R_{B}\left(x_{A}\right) \geq x_{A}$ iff $\beta+\alpha \geq x_{A}$. 
Thus for $\frac{x_{A}+x_{B}}{2} \in[\beta-\alpha, \beta+\alpha]$ the equilibrium candidates have to satisfy

$$
\begin{aligned}
x_{A} & =\left\{\begin{array}{cl}
0 & \text { if } 2(\beta-\alpha) \leq x_{B} \\
2(\beta-\alpha)-x_{B} & \text { if } 2(\beta-\alpha) \geq x_{B}
\end{array} \text { and } x_{B}=\left\{\begin{array}{cl}
2(\beta+\alpha)-x_{A} & \text { if } 2(\beta+\alpha)-1 \leq x_{A} \\
1 & \text { if } 2(\beta+\alpha)-1 \geq x_{A}
\end{array}\right.\right.
\end{aligned}
$$

which implies that for $\beta+\alpha \geq \frac{1}{2}$ we have $x_{A}=0$ and $x_{B}=1$, and for $\beta+\alpha \leq \frac{1}{2}$ we have $x_{A}=0$ and $x_{B}=2(\beta+\alpha)$. Notice that these two equilibrium candidates satisfy all the required conditions: $\beta+\alpha \geq x_{A}, \beta-\alpha \leq x_{B}$, and $\beta-\alpha \leq \frac{x_{A}+x_{B}}{2} \leq \beta+\alpha$.

Finally, suppose that we are in case c) thus we have that $\left(x_{A}, x_{B}\right)$ are such that $\frac{x_{A}+x_{B}}{2} \in[\beta+\alpha, 1]$. In this case, the probability of winning for party $A$ is given by $\pi_{A}\left(\frac{x_{A}+x_{B}}{2} ; \alpha, \beta\right)=\frac{x_{A}+x_{B}-4 \alpha}{2(1-2 \alpha)}$ and first order condition for party $A$ is $\left[\left(x_{B}\right)^{2}-\left(x_{A}\right)^{2}\right]-2 x_{A}\left(x_{A}+x_{B}-4 \alpha\right)=0$

which holds if and only if $x_{A}=\frac{4 \alpha-x_{B} \pm \sqrt{\left(x_{B}-4 \alpha\right)^{2}+3\left(x_{B}\right)^{2}}}{3}$. Since $\frac{4 \alpha-x_{B}-\sqrt{\left(x_{B}-4 \alpha\right)^{2}+3\left(x_{B}\right)^{2}}}{3}<0$ the best response for party $A$ is $B R_{A}\left(x_{B}\right)=\frac{4 \alpha-x_{B}+\sqrt{\left(x_{B}-4 \alpha\right)^{2}+3\left(x_{B}\right)^{2}}}{3}$. Notice that $B R_{A}\left(x_{B}\right) \geq 0, B R_{A}\left(x_{B}\right) \leq x_{B}$ for $2 \alpha \leq x_{B}$. The first order condition for party $B$ is $\left(1-x_{B}\right)^{2}-\left(1-x_{A}\right)^{2}+2\left(1-x_{B}\right)\left[2(1-2 \alpha)-\left(x_{A}+x_{B}-4 \alpha\right)\right]=0$

which holds if and only if $x_{B}=\frac{2+x_{A}}{3}$. Thus the best response for party $B$ is $B R_{B}\left(x_{A}\right)=\frac{2+x_{A}}{3}$. Notice that $B R_{B}\left(x_{A}\right) \leq 1$ and $B R_{B}\left(x_{A}\right) \geq x_{A}$.

Thus for $\frac{x_{A}+x_{B}}{2} \in[\beta+\alpha, 1]$ the equilibrium candidates have to satisfy $x_{A}=\frac{4 \alpha-x_{B}+\sqrt{\left(x_{B}-4 \alpha\right)^{2}+3\left(x_{B}\right)^{2}}}{3}$ and $x_{B}=\frac{2+x_{A}}{3}$ which implies that $x_{B}=\frac{5+3 \alpha \pm \sqrt{9 \alpha^{2}-2 \alpha+1}}{8}$.

First consider $x_{B}=\frac{5+3 \alpha-\sqrt{9 \alpha^{2}-2 \alpha+1}}{8}$ and notice that $\frac{x_{A}+x_{B}}{2}=2 x_{B}-1 \geq \beta+\alpha$ iff $\beta \leq \frac{5+3 \alpha-\sqrt{9 \alpha^{2}-2 \alpha+1}}{4}-1-\alpha$. Since $\frac{5+3 \alpha-{\sqrt{9 \alpha^{2}-2 \alpha+1}}^{2}}{4}-1-\alpha<0$ and we have assumed $\beta>0$

this cannot be an equilibrium candidate.

Next consider $x_{B}=\frac{5+3 \alpha+\sqrt{9 \alpha^{2}-2 \alpha+1}}{8}$ and notice that $\frac{x_{A}+x_{B}}{2}=2 x_{B}-1 \geq \beta+\alpha$ iff $\beta \leq \frac{5+3 \alpha+\sqrt{9 \alpha^{2}-2 \alpha+1}}{4}-1-\alpha$. Let $\beta \leq \frac{5+3 \alpha+\sqrt{9 \alpha^{2}-2 \alpha+1}}{4}-1-\alpha=\widetilde{\beta}(\alpha)$ be denoted as condition A. Notice that condition A implies $\beta+\alpha \leq \frac{5+3 \alpha+\sqrt{9 \alpha^{2}-2 \alpha+1}}{4}-1$ and we have that $\frac{1}{2} \leq \frac{5+3 \alpha+\sqrt{9 \alpha^{2}-2 \alpha+1}}{4}-1 \leq 1$. Observe that we also have $x_{B}=\frac{5+3 \alpha+\sqrt{9 \alpha^{2}-2 \alpha+1}}{8} \geq 2 \alpha$. Thus in this case we have that whenever condition $\mathrm{A}$ holds the equilibrium candidate is 


$$
x_{A}^{*}=3 \frac{5+3 \alpha+\sqrt{9 \alpha^{2}-2 \alpha+1}}{8}-2 \text { and } x_{B}^{*}=\frac{5+3 \alpha+\sqrt{9 \alpha^{2}-2 \alpha+1}}{8} .
$$

Observe that $\frac{\partial\left(\frac{5+3 \alpha+\sqrt{9 \alpha^{2}-2 \alpha+1}}{8}\right)}{\partial \alpha}>0$ for all $\alpha<\frac{1}{2} ; \frac{3}{4} \leq x_{B}^{*}=\frac{5+3 \alpha+\sqrt{9 \alpha^{2}-2 \alpha+1}}{8} \leq 1$ for all $\alpha<\frac{1}{2} ; \frac{1}{4} \leq x_{A}^{*}=3 \frac{5+3 \alpha+\sqrt{9 \alpha^{2}-2 \alpha+1}}{8}-2 \leq 1$ for all $\alpha<\frac{1}{2}$.

Next we have to check possible profitable deviations for the equilibrium candidates found in cases (b) and (c).

In case (b) we have $x_{A}=0$ and $x_{B}=1$ for $\beta+\alpha \geq \frac{1}{2}$ and $x_{A}=0$ and $x_{B}=2(\beta+\alpha)$ for $\beta+\alpha \leq \frac{1}{2}$. Notice that in this last case we have that $\frac{x_{A}+x_{B}}{2}=\beta+\alpha$ thus the analysis of case c) applies and generically the best response of party $A$ to $x_{B}=2(\beta+\alpha)$ is different that $x_{A}=0$, and the best response of party $B$ to $x_{A}=0$ is different that $x_{B}=2(\beta+\alpha)$. Thus, we can conclude that whenever $\beta+\alpha \leq \frac{1}{2}$ the equilibrium candidate is the one found in case $c)$.

For $\beta+\alpha \geq \frac{1}{2}$, the equilibrium candidate in case b) is $x_{A}=0$ and $x_{B}=1$. Clearly party $B$ does not have a profitable deviation unless party $A$ has one, thus we have to check whether in this case party $A$ has a profitable deviation given $x_{B}=1$, that is, whether $U_{A}\left(B R_{A}(1), 1\right)>U_{A}(0,1)$ where $B R_{A}(1)=\frac{4 \alpha-1+\sqrt{(1-4 \alpha)^{2}+3}}{3}$ whenever $\frac{B R_{A}(1)+1}{2} \geq \alpha+\beta$, that is, $\frac{2(1-\alpha)+\sqrt{(1-4 \alpha)^{2}+3}}{6} \geq \beta$.

We have that $U_{A}\left(B R_{A}(1), 1\right)>U_{A}(0,1)$ if and only if $\frac{\left(B R_{A}(1)+1-4 \alpha\right)\left(1-\left(B R_{A}(1)\right)^{2}\right)}{2}+\alpha>\beta$, which can be written as $\left[\left(1+\frac{(1-4 \alpha)^{2}}{3}\right)^{2}\left(4 \alpha-1+2 \sqrt{4 \alpha^{2}-2 \alpha+1}\right)+4-7 \alpha\right] \frac{1}{9}>\beta$

Let $\quad\left[\left(1+\frac{(1-4 \alpha)^{2}}{3}\right)\left(4 \alpha-1+2 \sqrt{4 \alpha^{2}-2 \alpha+1}\right)+4-7 \alpha\right] \frac{1}{9}=\bar{\beta}(\alpha)>\beta \quad$ be denoted as condition $\mathrm{B}$.

Thus we have that $x_{A}=0$ and $x_{B}=1$ is the unique pure strategy equilibrium for high enough values of $\beta$, that is, whenever condition $\mathrm{B}$ does not hold.

Finally, we have to check whether there are profitable deviations from the equilibrium candidate found in case (c): $x_{A}^{*}=3 \frac{5+3 \alpha+\sqrt{9 \alpha^{2}-2 \alpha+1}}{8}-2$ and $x_{B}^{*}=\frac{5+3 \alpha+\sqrt{9 \alpha^{2}-2 \alpha+1}}{8}$ which hold under condition A. Notice that a deviation to case (a) is not possible because $B R_{A}\left(x_{B}^{*}\right)=\frac{x_{B}^{*}}{3}$, and this means that $\frac{B R_{A}\left(x_{B}^{*}\right)+x_{B}^{*}}{2}=\frac{2}{3} x_{B}^{*} \geq \frac{1}{2}>\beta-\alpha$ since $x_{B}^{*} \geq \frac{3}{4}$. Thus we only have to consider deviations to case $\mathrm{b}$ ), that is, $x_{A}^{\prime}=2(\beta-\alpha)-x_{B}^{*}$.

Notice that $x_{A}=0$ is a deviation that leads to case (b) whenever $2(\beta-\alpha) \leq x_{B}^{*}$ or $\beta \leq \frac{5+3 \alpha+\sqrt{9 \alpha^{2}-2 \alpha+1}}{16}+\alpha$. Let $\hat{\hat{\beta}}(\alpha)=\frac{5+3 \alpha+\sqrt{9 \alpha^{2}-2 \alpha+1}}{16}+\alpha$. In this case, party $A$ can guarantee a probability of winning of $\frac{\beta-\alpha}{1-2 \alpha}$ by choosing $x_{A}=0$.

We have that $U_{A}\left(0, x_{B}^{*}\right)<U_{A}\left(x_{A}^{*}, x_{B}^{*}\right)$ if and only if 


$$
\frac{\beta-\alpha}{1-2 \alpha}\left(x_{B}^{*}\right)^{2}<\frac{2 x_{B}^{*}-1-2 \alpha}{1-2 \alpha}\left[\left(x_{B}^{*}\right)^{2}-\left(3 x_{B}^{*}-2\right)^{2}\right]
$$

which holds if and only if $\beta<\left(2 x_{B}^{*}-1-2 \alpha\right)\left[1-\frac{\left(3 x_{B}^{*}-2\right)^{2}}{\left(x_{B}^{*}\right)^{2}}\right]+\alpha$.

Let $\beta<\hat{\beta}(\alpha)=\left(2 x_{B}^{*}-1-2 \alpha\right)\left[1-\frac{\left(3 x_{B}^{*}-2\right)^{2}}{\left(x_{B}^{*}\right)^{2}}\right]+\alpha$ be denoted as condition $\mathrm{C}$. Notice that

$\widehat{\beta}(\alpha)<x_{B}^{*}-1-\alpha$ for all $\alpha<\frac{1}{2}$, thus condition $\mathrm{C}$ is below condition $\mathrm{A}$, that is $\hat{\beta}(\alpha)<\widetilde{\beta}(\alpha)$; and the intersection of condition $\mathrm{C}$ with $\beta \leq \widehat{\hat{\beta}}(\alpha)$ defines the set of parameter values for which the candidate of case c) is an equilibrium, that is $\beta \leq \overline{\bar{\beta}}(\alpha)=\min \{\widehat{\beta}(\alpha), \widehat{\hat{\beta}}(\alpha)\}$ Condition $\mathrm{B}$ :

$\beta<\frac{\left(B R_{A}(1)+1-4 \alpha\right)\left(1-\left(B R_{A}(1)\right)^{2}\right)}{2}+\alpha=\bar{\beta}(\alpha)$ with $B R_{A}(1)=\frac{4 \alpha-1+\sqrt{(1-4 \alpha)^{2}+3}}{3}$ implies that

$$
\begin{aligned}
& \bar{\beta}(0)=\frac{16}{27}>\frac{1}{2} \\
& \bar{\beta}\left(\frac{1}{4}\right)=\frac{17}{36}<\frac{1}{2} \\
& \bar{\beta}\left(\frac{1}{2}\right) \frac{1}{2} \\
& \frac{\partial \bar{\beta}(\alpha)}{\partial \alpha}=\left[4(1-4 \alpha)^{2}-3-\frac{2}{3}(1-4 \alpha)\left[8 \sqrt{4 \alpha^{2}-2 \alpha+1}+\frac{3+(1-4 \alpha)^{2}}{\sqrt{4 \alpha^{2}-2 \alpha+1}}\right]\right] \frac{1}{9} \\
& \frac{\partial \bar{\beta}(0)}{\partial \alpha}=\frac{1}{18}>0 \\
& \frac{\partial \bar{\beta}(1 / 4)}{\partial \alpha}=-\frac{1}{3}<0 \\
& \frac{\partial \bar{\beta}(1 / 2)}{\partial \alpha}=1>0
\end{aligned}
$$

Condition C:

$$
\beta \leq\left(2 x_{B}^{*}-1-2 \alpha\right)\left[1-\frac{\left(3 x_{B}^{*}-2\right)^{2}}{\left(x_{B}^{*}\right)^{2}}\right]+\alpha \text { with } x_{B}^{*}=\frac{5+3 \alpha+\sqrt{9 \alpha^{2}-2 \alpha+1}}{8} \text { implies that }
$$




$$
\begin{aligned}
& \beta \leq\left(\frac{1-5 \alpha+\sqrt{9 \alpha^{2}-2 \alpha+1}}{4}\right)\left[1-\frac{\left(3 \frac{5+3 \alpha+\sqrt{9 \alpha^{2}-2 \alpha+1}}{8}-2\right)^{2}}{\left(\frac{5+3 \alpha+\sqrt{9 \alpha^{2}-2 \alpha+1}}{8}\right)^{2}}\right]+\alpha=\hat{\beta}(\alpha) \\
& \widehat{\beta}(0)=\frac{4}{9}<\frac{1}{2} \\
& \widehat{\beta}\left(\frac{1}{4}\right)=\left(\frac{-1+\sqrt{17}}{16}\right)\left[\frac{504+34 \sqrt{17}}{(23+\sqrt{17})^{2}}\right]+\frac{1}{4}=0,41>\frac{1}{4} \\
& \widehat{\beta}\left(\frac{1}{2}\right)=\frac{1}{2} \\
& \frac{\partial \hat{\beta}(\alpha)}{\partial \alpha}=\left(\frac{-5+\frac{9 \alpha-1}{\sqrt{9 \alpha^{2}-2 \alpha+1}}}{4}\right)\left[1-\frac{\left(3 \frac{5+3 \alpha+\sqrt{9 \alpha^{2}-2 \alpha+1}}{8}-2\right)^{2}}{\left(\frac{5+3 \alpha+\sqrt{9 \alpha^{2}-2 \alpha+1}}{8}\right)^{2}}\right] \\
& -\left(\frac{1-5 \alpha+\sqrt{9 \alpha^{2}-2 \alpha+1}}{4}\right) \frac{\left(3 \frac{5+3 \alpha+\sqrt{9 \alpha^{2}-2 \alpha+1}}{8}-2\right) 3}{\left(\frac{5+3 \alpha+\sqrt{9 \alpha^{2}-2 \alpha+1}}{8}\right)}+1 \\
& \frac{\partial \widehat{\beta}(0)}{\partial \alpha}=-\frac{4}{3}-\frac{1}{2}+1=-\frac{5}{6} \\
& \frac{\partial \widehat{\beta}(1 / 4)}{\partial \alpha}=\left(\frac{-5+\frac{5}{\sqrt{17}}}{4}\right)\left[1-\frac{(5+3 \sqrt{17})^{2}}{(23+\sqrt{17})^{2}}\right]-\left(\frac{-1+\sqrt{17}}{16}\right) \frac{15+9 \sqrt{17}}{23+\sqrt{17}} \\
& +1=0,09 \\
& \frac{\partial \widehat{\beta}(1 / 2)}{\partial \alpha}=1
\end{aligned}
$$

Comparing conditions $\mathrm{B}$ and $\mathrm{C}$ we have that condition $\mathrm{B}$ lies above condition $\mathrm{C}$, that is $\bar{\beta}(\alpha)>\widehat{\beta}(\alpha)$.

See Fig. 3, where the light green line represents condition A, the red line represents condition $\mathrm{B}$, the dark green line represents condition $\mathrm{C}$, and the purple line represents $\hat{\hat{\beta}}(\alpha)$.

Therefore we have that when condition B does not hold, that is, for $\bar{\beta}(\alpha) \leq \beta$, there is a unique equilibrium in pure strategies with $x_{A}^{*}=0$ and $x_{B}^{*}=1$.

And for $\beta \leq \overline{\bar{\beta}}(\alpha)=\min \{\widehat{\beta}(\alpha), \hat{\hat{\beta}}(\alpha)\}$ there is a unique equilibrium in pure strategies with $x_{A}^{*}=3 \frac{5+3 \alpha+\sqrt{9 \alpha^{2}-2 \alpha+1}}{8}-2$ and $x_{B}^{*}=\frac{5+3 \alpha+\sqrt{9 \alpha^{2}-2 \alpha+1}}{8}$.

Notice that for $x_{A}^{*}=0$ and $x_{B}^{*}=1$ we have $\pi_{A}\left(\frac{x_{A}+x_{B}}{2} ; \alpha, \beta\right)=\frac{\beta-\alpha}{1-2 \alpha}<\frac{1}{2}$ iff $\beta<\frac{1}{2}$ and $U_{A}(0,1)=\frac{\beta-\alpha}{1-2 \alpha}-1<U_{B}(0,1)=-\frac{\beta-\alpha}{1-2 \alpha}$ 
And similarly for $x_{A}^{*}=3 \frac{5+3 \alpha+\sqrt{9 \alpha^{2}-2 \alpha+1}}{8}-2$ and $x_{B}^{*}=\frac{5+3 \alpha+\sqrt{9 \alpha^{2}-2 \alpha+1}}{8}$ we have $\frac{x_{A}^{*}+x_{B}^{*}}{2}=\frac{2+6 \alpha+2 \sqrt{9 \alpha^{2}-2 \alpha+1}}{8}$ and

$\pi_{A}\left(\frac{x_{A}^{*}+x_{B}^{*}}{2} ; \alpha, \beta\right)=\frac{2-10 \alpha+2 \sqrt{9 \alpha^{2}-2 \alpha+1}}{8(1-2 \alpha)}<\frac{1}{2}$ iff $\alpha<\frac{1}{2}$

and since $x_{A}^{*}>1-x_{B}^{*}$ we also must have $U_{A}\left(x_{A}^{*}, x_{B}^{*}\right)<U_{B}\left(x_{A}^{*}, x_{B}^{*}\right)$.

Proof of proposition 3 If $\sigma=1$ and $\alpha>0$ then the decisive voter's utility function is given by:

$$
u_{m}(x, y)=-\sigma\left(x-x_{m}\right)^{2}-(1-\sigma)\left(y-y_{m}\right)^{2}=-\left(x-x_{m}\right)^{2}
$$

and the probability of winning for party $\mathrm{A}$ is given by

$$
\pi_{L}\left(\left(x_{A}, y_{A}\right),\left(x_{B}, y_{B}\right)\right)=\left\{\begin{array}{cl}
0 & \text { if } \frac{x_{L}+x_{R}}{2} \in[0,2 \alpha] \\
\frac{x_{L}+x_{R}-4 \alpha}{2(1-2 \alpha)} & \text { if } \frac{x_{L}+x_{R}}{2} \in(2 \alpha, 1]
\end{array}\right.
$$

If $\alpha>0$ then $f(x, \alpha)=\left\{\begin{array}{cl}0 & \text { if } x \in[0,2 \alpha) \\ \frac{1}{1-2 \alpha} & \text { if } x \in[2 \alpha, 1]\end{array}\right.$. Thus, for every pair of policy choices $\left(x_{A}, x_{B}\right) \in X^{2}$ we have that the probability of winning for party $A$ is given by

$$
\pi_{A}\left(x_{A}, x_{B}\right)=\left\{\begin{array}{cl}
0 & \text { if } \frac{x_{A}+x_{B}}{2} \in[0,2 \alpha] \\
\frac{x_{A}+x_{B}-4 \alpha}{2(1-2 \alpha)} & \text { if } \frac{x_{A}+x_{B}}{2} \in(2 \alpha, 1]
\end{array}\right.
$$

and the probability of winning for party $B$ is given by

$$
\pi_{B}\left(x_{A}, x_{B}\right)=1-\pi_{A}\left(x_{A}, x_{B}\right)=\left\{\begin{array}{cl}
1 & \text { if } \frac{x_{A}+x_{B}}{2} \in[0,2 \alpha] \\
\frac{2-x_{A}-x_{B}}{2(1-2 \alpha)} & \text { if } \frac{x_{A}+x_{B}}{2} \in(2 \alpha, 1]
\end{array}\right.
$$

In order to compute the probability of winning of the two parties we have to consider two cases:

(a) those $\left(x_{A}, x_{B}\right)$ such that $\frac{x_{A}+x_{B}}{x^{2} x_{B}} \in(2 \alpha, 1]$, that is, $4 \alpha<x_{A}+x_{B} \leq 2$; and

(b) those $\left(x_{A}, x_{B}\right)$ such that $\frac{x_{A} 2 x_{B}}{2} \in[0,2 \alpha]$, that is, $0 \leq x_{A}+x_{B} \leq 4 \alpha$.

First suppose that we are in case a) and $\left(x_{A}, x_{B}\right)$ are such that $\frac{x_{A}+x_{B}}{2} \in(2 \alpha, 1]$. In this case, parties' payoffs functions are given by

$$
\begin{aligned}
& U_{A}\left(x_{A}, x_{B}\right)=\frac{x_{A}+x_{B}-4 \alpha}{2(1-2 \alpha)}\left[-\left(x_{A}\right)^{2}+\left(x_{B}\right)^{2}\right]-\left(x_{B}\right)^{2} \\
& U_{B}\left(x_{A}, x_{B}\right)=\frac{x_{A}+x_{B}-4 \alpha}{2(1-2 \alpha)}\left[\left(1-x_{B}\right)^{2}-\left(1-x_{A}\right)^{2}\right]-\left(1-x_{B}\right)^{2}
\end{aligned}
$$

and their first order conditions are: 


$$
\begin{aligned}
& \frac{\partial U_{A}\left(x_{A}, x_{B}\right)}{\partial x_{A}}=\frac{1}{2(1-2 \alpha)}\left[-\left(x_{A}\right)^{2}+\left(x_{B}\right)^{2}\right]-\frac{x_{A}+x_{B}-4 \alpha}{2(1-2 \alpha)} 2 x_{A}=0 \\
& \frac{\partial U_{A}\left(x_{A}, x_{B}\right)}{\partial x_{B}}=\frac{1}{2(1-2 \alpha)}\left[\left(1-x_{B}\right)^{2}-\left(1-x_{A}\right)^{2}\right] \\
& -\frac{x_{A}+x_{B}-4 \alpha}{2(1-2 \alpha)} 2\left(1-x_{B}\right)+2\left(1-x_{B}\right)=0
\end{aligned}
$$

The second order conditions are:

$\frac{\partial^{2} U_{A}\left(x_{A}, x_{B}\right)}{\partial\left(x_{A}\right)^{2}}=-\frac{1}{(1-2 \alpha)}\left(3 x_{A}+x_{B}-4 \alpha\right)<0$ for $3 x_{A}+x_{B}>4 \alpha$ which is satisfied since $\frac{x_{A}+x_{B}}{2} \in(2 \alpha, 1]$

$$
\frac{\partial^{2} U_{A}\left(x_{A}, x_{B}\right)}{\partial\left(x_{B}\right)^{2}}=\frac{x_{A}+3 x_{B}-4}{(1-2 \alpha)}<0
$$

Their reaction functions are as follows. For party $A$

$$
x_{A}\left(x_{B}\right)=\frac{\left(4 \alpha-x_{B}\right)+\sqrt{4\left[\left(x_{B}-2 \alpha\right)^{2}+2 \alpha x_{B}\right]}}{3}
$$

with

$$
\begin{aligned}
& x_{A}\left(x_{B}\right) \geq 0 \\
& x_{A}\left(x_{B}\right) \leq x_{B} \text { if } x_{R} \geq 2 \alpha \\
& \frac{\partial x_{A}\left(x_{B}\right)}{\partial x_{B}} \geq 0 \text { iff } x_{R}>2 \alpha \\
& \frac{\partial x_{A}\left(x_{B}\right)}{\partial \alpha} \geq 0
\end{aligned}
$$

For party $B$

$$
x_{B}\left(x_{A}\right)=\frac{2+x_{A}}{3}
$$

with

$$
\begin{aligned}
& x_{B}\left(x_{A}\right) \leq 1 \\
& x_{B}\left(x_{A}\right) \geq x_{A} \\
& \frac{\partial x_{B}\left(x_{A}\right)}{\partial x_{A}} \geq 0 \\
& \frac{\partial x_{B}\left(x_{A}\right)}{\partial a}=0
\end{aligned}
$$

Next suppose that $\left(x_{A}, x_{B}\right)$ are such that $\frac{x_{A}+x_{B}}{2} \in[0,2 \alpha]$, that is, $0 \leq x_{A}+x_{B} \leq 4 \alpha$. 
Notice that if $x_{B} \leq 2 \alpha$ we have that $B R_{A}\left(x_{B} \leq 2 \alpha\right)=\left[0, x_{B}\right]$ because $U_{A}\left(x_{A}, x_{B}\right)=-\left(x_{B}\right)^{2}>-\left(\hat{x}_{A}\right)^{2}=U_{A}\left(\hat{x}_{A}, x_{B}\right)$ for all $x_{A} \in\left[0, x_{B}\right]$ and for all $\hat{x}_{A}$ $\in\left(x_{B}, 1\right]$. Thus, parties' payoff functions are given by

$$
\begin{aligned}
& U_{A}\left(x_{A}, x_{B}\right)=-\left(x_{B}\right)^{2} \\
& U_{B}\left(x_{A}, x_{B}\right)=-\left(1-x_{B}\right)^{2}
\end{aligned}
$$

If $x_{B}>2 \alpha$ we have that the only best response of party $A$ is

$$
B R_{A}\left(x_{B}>2 \alpha\right)=x_{A}\left(x_{B}\right)=\frac{\left(4 \alpha-x_{B}\right)+\sqrt{4\left[\left(x_{B}-2 \alpha\right)^{2}+2 \alpha x_{B}\right]}}{3}
$$

and notice that $x_{A}\left(x_{B}\right)+x_{B} \geq 4 \alpha$, because in this case the policy outcome is a convex combination of $x_{B}$ and $x_{A}\left(x_{B}\right)<x_{B}$ which leads to better payoffs for party $A$ than any $x_{A}$ such that $0 \leq x_{A}+x_{B} \leq 4 \alpha$ that produces $U_{A}\left(x_{A}, x_{B}\right)=-\left(x_{B}\right)^{2}$. Therefore, party A reaction function is given by:

$$
B R_{A}\left(x_{B}\right)=\left\{\begin{array}{cl}
\frac{\left(4 \alpha-x_{B}\right)+\sqrt{4\left[\left(x_{B}-2 \alpha\right)^{2}+2 \alpha x_{B}\right]}}{\left[0, x_{R}\right]} & \text { if } x_{B}>2 \alpha \\
\text { if } x_{B} \leq 2 \alpha
\end{array}\right.
$$

Regarding $B$ we have that if $x_{A} \leq 2 \alpha$ then $B R_{B}\left(x_{A}\right)=\max \left\{4 \alpha-x_{A}, \frac{2+x_{A}}{3}\right\}$. Otherwise, if $x_{A}>2 \alpha$ then $B R_{B}\left(x_{A}\right)=\frac{2+x_{A}}{3}$.Therefore, party $\mathrm{B}$ reaction function is given by:

$$
B R_{B}\left(x_{A}\right)=\left\{\begin{array}{cc}
\frac{2+x_{A}}{3} & \text { if } x_{A}>\frac{6 \alpha-1}{2} \\
4 \alpha-x_{A} & \text { if } 4 \alpha-1<x_{A}<\frac{6 \alpha-1}{2} \\
1 & \text { if } 4 \alpha-1>x_{A}
\end{array}\right.
$$

Notice that for $\alpha<\frac{1}{6}$ we have that $B R_{B}\left(x_{A}\right)=\frac{2+x_{A}}{3}$, and for $\alpha<\frac{1}{4}$ we always have $B R_{B}\left(x_{A}\right)<1$.

Thus, in equilibrium we will have that $2 \alpha<\frac{x_{A}^{*}+x_{B}^{*}}{2}$ and :

$$
x_{A}^{*}=\frac{18 \alpha-2+\sqrt{(2-18 \alpha)^{2}+32}}{16} \text { and } x_{B}^{*}=\frac{2+\frac{18 \alpha-2+\sqrt{(2-18 \alpha)^{2}+32}}{16}}{3} .
$$

with 


$$
\begin{aligned}
& \frac{\partial x_{A}^{*}}{\partial \alpha}>0 \\
& \frac{\partial x_{B}^{*}}{\partial \alpha}>0 \\
& \frac{\partial x_{A}^{*}}{\partial \alpha}=3 \frac{\partial x_{B}^{*}}{\partial \alpha}>\frac{\partial x_{B}^{*}}{\partial \alpha} \\
& x_{A}^{*} \leq x_{B}^{*} \\
& x_{A}^{*} \leq \frac{1+2 \alpha}{2} \leq x_{B}^{*} \\
& \lim _{\alpha \rightarrow 1 / 2} x_{A}^{*}=1 ; \lim _{\alpha \rightarrow 1 / 2} x_{B}^{*}=1 \\
& 4 \alpha<x_{A}^{*}+x_{B}^{*} \leq 2 \\
& \frac{\partial\left(x_{A}^{*}+x_{B}^{*}\right)}{\partial \alpha}=\frac{4}{3} \frac{\partial x_{A}^{*}}{\partial \alpha}>0 \\
& x_{A}^{*}+x_{B}^{*}>1 \\
& \frac{1+2 \alpha}{2}-x_{A}^{*}>x_{B}^{*}-\frac{1+2 \alpha}{2} \\
& \frac{\partial\left(x_{B}^{*}-x_{A}^{*}\right)}{\partial \alpha}=-\frac{2}{3} \frac{\partial x_{A}}{\partial \alpha}<0 \\
& \pi_{A}=\frac{1+2 x_{A}-6 \alpha}{3(1-2 \alpha)}=\frac{6-30 \alpha+\sqrt{(2-18 \alpha)^{2}+32}}{24(1-2 \alpha)}<\frac{1}{2} \\
& 1-\pi_{A}=1-\frac{1+2 x_{A}-6 \alpha}{3(1-2 \alpha)}=\frac{2\left(1-x_{A}\right)}{3(1-2 \alpha)}=\frac{18-18 \alpha+\sqrt{(2-18 \alpha)^{2}+32}}{24(1-2 \alpha)} \\
& \frac{\partial \pi_{A}}{\partial \alpha}<0 \\
& \frac{\partial U_{A}\left(x_{A}, x_{B}\right)}{\partial \alpha}<0 \\
& \frac{\partial U_{B}\left(x_{A}, x_{B}\right)}{\partial \alpha}>0 .
\end{aligned}
$$

Funding Open Access funding provided thanks to the CRUE-CSIC agreement with Springer Nature.

Open Access This article is licensed under a Creative Commons Attribution 4.0 International License, which permits use, sharing, adaptation, distribution and reproduction in any medium or format, as long as you give appropriate credit to the original author(s) and the source, provide a link to the Creative Commons licence, and indicate if changes were made. The images or other third party material in this article are included in the article's Creative Commons licence, unless indicated otherwise in a credit line to the 
material. If material is not included in the article's Creative Commons licence and your intended use is not permitted by statutory regulation or exceeds the permitted use, you will need to obtain permission directly from the copyright holder. To view a copy of this licence, visit http://creativecommons.org/licen ses/by/4.0/.

\section{References}

Ansolabehere S, Puy MS (2018) Measuring issue-salience in voters preferences. Elect Stud $51: 103-114$

Aragones E (2007) The key party in the Catalan government. SpanEconRev 9:249-271

Aragones E, Ponsati C (2016) Negotiations and political strategies in the contest for Catalan independence. In: Catalonia: a new independent state in Europe? edited by Xavier Cuadras-Morat ó, Routledge editors

Balcells L, Torrats-Espinosa G (2018) Using a natural experiment to estimate the electoral consequences of terrorist attacks. Proc Natl Acad Sci 115(42):10624-10629

Bali V (2007) Terror and elections: lessons from Spain. Elect Stud 26(3):669-687

Bangartner F, Jones BD (1993) Agenda and instability in American politics. Chicago University Press, Chicago

Barbera P, Casas A, Nagler J, Egan PJ, Bonneau R, Jost JT, Tucker J (2019) Who leads? Who follows? Measuring the issue attention and agenda setting by legislators and the mass public using social media data. forthcoming in American Political Science Review

Bartels LM (2006) Priming and persuasion in presidential campaigns. In: Brady HE, Johnston R (eds) Capturing campaign effects. University of Michigan Press, Ann Arbor, pp 78-112

Birkland TA (2017) Agenda setting in public policy. Handbook of public policy analysis, Routledge, $89-104$

Birkland TA (1998) Focusing events, mobilization, and agenda setting. J Publ Policy 18(1):53-74

Boomgaarden HG, de Vreese CH (2007) Dramatic real-world events and public opinion dynamics: media coverage and its impact on public reactions to an assassination. Int J Pub Opin Res 19(3):354-366

Calvert R (1985) Robustness of the multidimensional voting model, candidate motivations, uncertainty and convergence. Am J Polit Sci 39:69-95

Clinton JD (2006) Representation in congress: constituents and roll calls in the 106th house. J Polit 68(2):397-409

Downs A (1957) An economic theory of democracy. Harper \& Row, New York

Guinjoan M, Rodon T (2016) Catalonia at the crossroads: analysis of the increasing support for secession. In: Catalonia: a new independent state in Europe? edited by Xavier Cuadras-Morat ó, Routledge editors

Hofstetter CR (1969) Political disengagement and the death of Martin Luther King. Pub Opin Quart 33(2):174-179

Iyengar S (1990) The accessibility bias in politics: television news and public opinion. Int J Pub Opin Res 2:1-15

Iyengar S, Kinder DR (1987) News that matters: television and American opinion. University of Chicago Press, Chicago

Iyengar S, Kinder DR, Peters MD (1982) Experimental demonstrations of the not-so-minimal consequences of television news programs. Am Polit Sci Rev 76(4):848-58

Kahneman D, Tversky A (1979) Prospect theory: an analysis of decision under risk. Econometrica 47(2):263-91

Kahneman D, Tversky A (1981) The framing of decisions and the psychology of choice. Science 211(4481):453-58

Kahneman D, Tversky A (1984) Choices, values and frames. Am Psychol 39(4):341-50

Kastellec JP, Lax JR, Malecki M, Phillips JH (2015) Polarizing the electoral connection: partisan representation in supreme court confirmation politics. J Polit 77(3):787-804

Kingdon JW (1995) Agenda, alternatives and public policies, 2nd edn. Harper Collins, New York

Krosnick JA, Kinder DR (1990) Altering the foundations of support for the president through priming. Am Polit Sci Rev 84(2):497-512

Lago I, Montero JR (2005) The mechanics of electoral change. Claves de la razón práctica 149:36-44 
Lenz GS (2009) Learning and opinion change, not priming: reconsidering the priming hypothesis. Am J Polit Sci 53(4):821-37

Montalvo JG (2011) Voting after the bombings: a natural experiment on the effect of terrorist attacks on democratic elections. Rev Econ Stat 93(4):1146-1154

Montalvo JG (2012) Re-examining the evidence on the electoral impact of terrorist attacks: the Spanish election of 2004. Elect Stud 31:96-106

Muñoz J, Falcó-Gimeno A, Herná ndez E (2019) Unexpected event during survey design: promise and pitfalls for causal inference. forthcoming in Political Analysis

Neundorf A, Adams J (2018) The micro-foundations of party competition and issue ownership: the reciprocal effects of citizens issue salience and party attachments. Br J Polit Sci 48(2):385-406

Plümper T, Epifanio M (2015) The issue-salience effect in counterterrorist politics. Working paper

Sheafer T, Weimann G (2005) Agenda building, agenda setting, priming, individual voting intentions, and the aggregate results: an analysis of four Israeli elections. J Commun 55(2):347-65

Slovic P, Lichtenstein S, Fischhoff B (1984) Modeling the societal impact of fatal accidents. Manage Sci 30:464-474

van der Brug W (2001) Perceptions, opinions and party preferences in the face of a real world event: chernobyl as a natural experiment in political psychology. J Theor Polit 13:53-80

Walker JL (1977) Setting the agenda in the US Senate: a theory of problem selection. Br J Polit Sci 7:423-445

Wittman D (1977) Candidates with policy preferences: a dynamic model. J Econ Theory 15:86-103

Wittman D (1983) Candidate motivation: a synthesis of alternatives. Am Polit Sci Rev 77:142-57

Publisher's Note Springer Nature remains neutral with regard to jurisdictional claims in published maps and institutional affiliations. 